\title{
Corrigendum: Trends in Incidence and Mortality of Waldenström Macroglobulinemia: A Population- Based Study
}

\author{
Xuejiao Yin ${ }^{1}$, Lei Chen ${ }^{1}$, Fengjuan Fan ${ }^{1}$, Han Yan ${ }^{1}$, Yuyang Zhang ${ }^{1}$, Zhenli Huang ${ }^{1}$, \\ Chunyan Sun ${ }^{1,2 *}$ and $\mathrm{Yu} \mathrm{Hu}^{1,2 *}$ \\ 1 Institute of Hematology, Union Hospital, Tongji Medical College, Huazhong University of Science and Technology, Wuhan, \\ China, ${ }^{2}$ Collaborative Innovation Center of Hematology, Huazhong University of Science and Technology, Wuhan, China
}

\section{OPEN ACCESS}

Approved by:

Frontiers Editorial Office,

Frontiers Media SA, Switzerland

${ }^{*}$ Correspondence:

Chunyan Sun

suncy0618@163.com

Yu Hu

dr_huyu@126.com

Specialty section:

This article was submitted to Hematologic Malignancies, a section of the journal

Frontiers in Oncology

Received: 22 January 2021 Accepted: 22 January 2021 Published: 18 February 2021

Citation:

Yin $X$, Chen L, Fan F, Yan $H$, Zhang $Y$, Huang Z, Sun C and Hu Y (2021) Corrigendum: Trends in Incidence and Mortality of Waldenström Macroglobulinemia: A Population-Based Study.

Front. Oncol. 11:657016. doi: 10.3389/fonc.2021.657016
Keywords: Waldenström macroglobulinemia, surveillance, epidemiology, and end results (SEER), incidence, incidence-based mortality, epidemiology, survival

\section{A Corrigendum on}

Trends in Incidence and Mortality of Waldenström Macroglobulinemia: A Population-Based Study

by Yin X, Chen L, Fan F, Yan H, Zhang Y, Huang Z, Sun C and Hu Y (2020). Front. Oncol. 10:1712. doi: $10.3389 /$ fonc.2020.01712

In the published article, there was an incorrect expression of affiliation 1. Instead of "Tongji Medical College, Institute of Hematology, Union Hospital, Huazhong University of Science and Technology, Wuhan, China", it should be "Institute of Hematology, Union Hospital, Tongji Medical College, Huazhong University of Science and Technology, Wuhan, China".

The authors apologize for this error and state that this does not change the scientific conclusions of the article in any way. The original article has been updated.

Copyright $\odot 2021$ Yin, Chen, Fan, Yan, Zhang, Huang, Sun and Hu. This is an open-access article distributed under the terms of the Creative Commons Attribution License (CC BY). The use, distribution or reproduction in other forums is permitted, provided the original author(s) and the copyright owner(s) are credited and that the original publication in this journal is cited, in accordance with accepted academic practice. No use, distribution or reproduction is permitted which does not comply with these terms. 